\title{
Environnements, cultures et développements
}

Lucie Sauvé et Renée Brunelle

\section{(2) OpenEdition}

\section{Journals}

Édition électronique

URL : http://journals.openedition.org/ere/4732

DOI : $10.4000 /$ ere.4732

ISSN : 2561-2271

Éditeur

Centr'ERE

Référence électronique

Lucie Sauvé et Renée Brunelle, «Environnements, cultures et développements », Éducation relative à l'environnement [En ligne], Volume 4 | 2003, mis en ligne le 14 septembre 2003, consulté le 24 septembre 2020. URL : http://journals.openedition.org/ere/4732 ; DOI : https://doi.org/10.4000/ere. 4732

Ce document a été généré automatiquement le 24 septembre 2020. 


\title{
Environnements, cultures et développements
}

\author{
Lucie Sauvé et Renée Brunelle
}

1 L'évolution des paysages de notre petite planète et celle des conditions environnementales de nos milieux de vie montrent bien à quel point notre espèce humaine et les sociétés que nous formons sont partie intégrante de l'écosphère : il n'y a pas « la nature » d'un côté et « la nature humaine » de l'autre. Certes, nous sommes une manifestation particulière de la nature, avec une extraordinaire capacité de réflexivité et d'agir, mais nous faisons partie de Gaïa, pour le meilleur et le pire. Pour le meilleur, lorsque notre créativité se joint aux autres forces créatives de la nature, inventant des espaces d'harmonie et des conditions de mieux-être; mais aussi pour le pire, comme nous le montrent par exemple l'impact de nos modes de production et de consommation ou les effets dévastateurs de toutes les formes de guerres.

2 Nos cultures sont une manifestation de la nature. Elles se forment à partir des caractéristiques particulières du milieu de vie des populations, comme en témoignent les vêtements, la nourriture, l'habitat, les chansons, etc. En retour, les populations (d'origine ou migrantes) valorisent et préservent les espèces, les lieux et les paysages qui ont pour elles une signification, une utilité, une valeur culturelle en somme. Le concept de « diversité bioculturelle » met en évidence les liens étroits entre la diversité biologique et la diversité culturelle. Très souvent, les zones riches en diversité biologique sont également des zones riches en diversité culturelle, dont la diversité linguistique est un indicateur.

Nous ne sommes pas seulement liés à la nature, nous sommes la nature [...]. La société humaine est un sous-système de l'écosphère, les êtres humains sont enchâssés dans la nature [...]. Si l'humanité fait partie du tissu de la nature, l'environnement n'est plus la toile de fond scénique, mais devient le sujet de la pièce elle-même [...]. Il nous faut apprendre à vivre comme partie de la nature. L'économie devient enfin l'écologie humaine. (Wackernagel et Rees, 1999, p. 24-25) Libérer la nature dans un sens révolutionnaire ne signifie pas la mettre à la place de la société au centre de notre civilisation [...] c'est élargir l'horizon de notre vie et de notre monde et donner à ceux-ci les deux foyers que sont la société ET la nature. Libérer la nature, c'est couper court à cette obsession des temps modernes qui veut 
la désenchanter, l'isoler comme si nous n'avions pas grand-chose en commun avec elle [...]. Fruerbach exprime avec force : «Je me sens dépendre de la nature, parce que je me sens dépendre des autres humains; si je n'avais pas besoin d'eux, je n'aurais pas besoin du monde; voilà qui me réconcilie avec lui ». [Dans un projet de] transformation de nos modes de vie [...] nature et société sont mises sur le même plan, façonnées à l'unisson. La culture qui exclut la nature est en apparence au bout de son rouleau. La nature fera partie de la culture à venir. Ses contours ne sont pas encore perceptibles, mais son sens l'est déjà : réenchanter le monde (Moscovici, 2002, p. 123).

3 Ainsi nos environnements, ceux des villes, des milieux agricoles, des régions montagneuses, des zones littorales, etc., se construisent sur une trame à double dimension, celles de la nature et de la culture (qui exprime l'humain dans la nature). À la fois, ils déterminent notre rapport au monde comme ils témoignent de ce dernier. Ils induisent comme ils traduisent les caractères fondamentaux de nos rapports sociaux, de nos « choix de société », de nos « modes de développement ».

Or nos choix de sociétés, modelés par cette idée moderne du « développement », cette « croyance occidentale » que déconstruit Gilbert Rist (1996), ont conduit à une érosion des cultures, à l'instauration (par invasion) d'une monoculture planétaire. Et celle-ci va de pair avec la destruction des écosystèmes et l'érosion de la diversité biologique, avec la détérioration de la qualité de l'environnement, notre maison de vie partagée. Légitimée par l'argument que le développement économique résoudra les problèmes sociaux et environnementaux, cette monoculture se répand comme un nouveau dogme. Elle accroît l'exploitation et la dépendance des populations, elle alimente l'inégalité et les ruptures au sein des sociétés comme entre les sociétés.

Désormais dit-on, on ne peut plus séparer l'idée d'environnement de celle de développement : l'environnement est la ressource du développement, comme elle en est aussi le facteur limitant dont il faut bien tenir compte. Une telle conception, considérée comme allant de soi, correspond pourtant à une vision du monde particulière, à cette culture dominante que nous venons d'évoquer et qui témoigne d'un certain rapport entre société et nature. Une remise en question s'impose et ce Volume 4 de la revue Éducation relative l'environnement veut y contribuer par divers Regards, Recherches et Réflexions.

6 Le thème "Environnements, cultures et développements " invite les auteurs de ce volume à clarifier le réseau des notions associées à ces trois univers conceptuels et à explorer la pluralité des conceptions possibles, la complexité des relations qui se tissent entre ces trois pôles, la diversité des projets qui en découlent et l'importance des enjeux qui émergent, plus spécifiquement en ce qui a trait à l'éducation. Ils sont invités à adopter une distance critique à l'égard des moules à penser et des " mots d'ordre $»^{1}$ contemporains, à faire entre autres l'effort de penser et de dire les choses autrement que dans le langage de la durabilité ou de la soutenabilité, trop souvent utilisé dans une perspective a-critique.

7 En effet, si le « compromis » du développement durable ${ }^{2}$ convient à certains contextes et apparaît pertinent pour amorcer un dialogue avec certains acteurs sociaux de la sphère économique et politique, il importe de reconnaître qu'un tel cadre de référence (culturellement déterminé) reste beaucoup trop étroit ou nettement inadéquat pour interpréter, inspirer ou donner un sens à l'ensemble des dimensions de notre rapport à l'environnement ${ }^{3}$. Or l'une des dérives de la proposition du développement durable est justement celle de confondre une stratégie (dont la pertinence dépend du contexte) 
avec un projet de société, voire une finalité de notre humanité. S'il faut «Défaire le développement, refaire le monde $»^{4}$, il importe en effet de déconstruire les discours et les propositions dominantes, et faire l'effort de penser autrement et de construire ailleurs, "au-delà du développement» comme nous y invite Gustavo Esteva (1996). Parmi les éléments de discours qui méritent d'être questionnés, mentionnons entre autres ceux qui sont associés à l'idée de "capital social ", de "ressources humaines ", de "stock de ressources naturelles", de "gestion de la nature", de "gestion de l'environnement » ou encore d'« économie du savoir ».

C'est donc à une telle invitation qu'ont répondu les 31 auteurs de ce volume thématique. Certains proposent une réflexion générale d'ordre épistémologique, éthique ou pédagogique; d'autres adoptent une perspective environnementale ou éducationnelle pour se pencher sur des réalités particulières, formant un ensemble riche de diversité : réalités tantôt urbaines, tantôt rurales, littorales ou de montagne ... dans diverses régions du monde, en Afrique sahélienne, autour de la Méditerranée, en Amérique du Nord, en Europe, en Amérique latine. La diversité des regards, recherches et réflexions permet de jeter un meilleur éclairage sur la question complexe des multiples rapports entre environnement, culture et développement. En filigrane, les textes témoignent aussi de la culture éducationnelle et environnementale des auteurs eux-mêmes, ce qui offre l'intérêt d'accéder à un autre niveau de lecture de cet ouvrage collectif. Dans l'ensemble, celui-ci offre de nombreux éléments pour enrichir le champ théorique et pratique de l'éducation relative à l'environnement, dont la mission première est celle de stimuler le regard critique sur les fondements de nos rapports au monde, à la base d'un agir éclairé, cohérent et responsable.

Bonne lecture!

\section{BIBLIOGRAPHIE}

Esteva, G. (1996). Au-delà du développement. In W. Sach et G. Esteva (dir.), Des ruines du développement. Montréal : Éditions Écosociétés, p. 87-138.

Moscovici, S. (2002). De la nature. Pour penser l'écologie. Paris : Éditions Métaillé.

Rist, G. (1996). Le développement. Histoire d'une croyance occidentale. Paris : Presses de Sciences Po. Traore, A. (2002). Le viol de l'imaginaire. Paris et Arles : Fayard et Actes Sud.

Vaillancourt, J.-G. (1995). Penser et concrétiser le développement durable. Écodécision, 15, 24-29.

Wackernagel, M. et Rees, W. (1999). Notre empreinte écologique. Comment réduire les conséquences de l'activité humaine sur la Terre. Montréal : Éditions Écosociétés.

\section{NOTES}

1. Aminata Traore (2002) identifie les «mots d'ordre » qui s'imposent aux sociétés africaines, et violent leur imaginaire, leur capacité de voir et d'inventer leur monde autrement. 
2. Jean-Guy Vaillancourt (1995) explique la genèse du concept de développement durable, qu'il situe dans un contexte historique et socio-politique particulier.

3. La proposition du développement durable sépare économie et société comme deux sphères distinctes: l'économie détermine les rapports entre société et environnement. Par ailleurs, l'environnement est essentiellement envisagé comme un réservoir de ressources, au service de l'économie, condition du développement humain.

4. Il s'agit du titre d'un colloque organisé en 2002 par La Ligne d'horizon (Association des amis de François Partant), Le Monde diplomatique et l'UNESCO (Programme Most) : http://www.apresdeveloppement.org/html2/listes/colloque.htm. 